DE

M E D I C I N A

T R O P I C A L

$\mathrm{DE}$

SÃO PAULO

JOURNAL OF THE SÃO PAULO INSTITUTE OF TROPICAL MEDICINE

(1) Instituto Butantan, Laboratório de Fisiopatologia, São Paulo, São Paulo,Brazil

(2) Hospital São Vicente de Paulo, Passo

Fundo, Rio Grande do Sul, Brazil

(3) Instituto Venezolano de Investigaciones

Científicas, Caracas, Venezuela

(4) Instituto Butantan, Laboratório Especial de Coleções Zoológicas, São Paulo, São Paulo, Brasil

(5) Hospital de Clínicas de Porto Alegre, Porto Alegre, Rio Grande do Sul, Brazil

Correspondence to: Ida Sigueko SanoMartins

Instituto Butantan, Laboratório de Fisiopatologia, Av. Vital Brazil, 1500, CEP 05503- 900, São Paulo,SP, Brazil.

Tel: +55 1126279565 , fax +551126279581

E-mail: ida.sano@butantan.gov.br and sanomartins@gmail.com

Received: 21 Nov 2016

Accepted: 30 March 2017

\section{Hemostatic disorders induced by skin contact with Lonomia obliqua (Lepidoptera, Saturniidae) caterpillars}

Ida Sigueko Sano-Martins ${ }^{1}$, Alaour Candida Duarte², Belsy Guerrero ${ }^{3}$, Roberto Henrique Pinto Moraes ${ }^{4}$, Elvino José Guardão Barros ${ }^{5}$, Carmen Luisa Arocha-Piñango ${ }^{3}$

\section{ABSTRACT}

Patients envenomed by Lonomia sp caterpillars initially experience a mild burning pain, headache, nausea, vomiting, and skin and mucosal hemorrhages. Some patients can rapidly progress to a severe coagulopathy that presents as visceral or intracerebral hemorrhaging. We studied the hemostatic alterations that occurred in 14 patients who were envenomed by Lonomia obliqua in Southern Brazil and presented at the Hospital São Vicente de Paulo (Passo Fundo, RS), Brazil during the summers of 1993 and 1994 when Lonomia antivenom was not yet available for treatment. The patients were classified into to 4 clinical groups: 0 (two patients), I (eight patients), II (two patients), and III (two patients). The patients were admitted to the hospital between 4 hours and five days after contact with the caterpillars. In this study, the coagulation parameters of the patients were followed up for up to 172 hours after the accidents. The patients received no treatment with the exceptions of two patients who received blood transfusions and antifibrinolytic treatment. The observed abnormalities related to blood coagulation and fibrinolytic factors were similar regardless of the severity of the bleeding symptoms. These findings suggest that alterations in hemostatic parameters without thrombocytopenia are not predictors of the seriousness of such accidents. Thus, consumptive disorder and reactive fibrinolysis are not proportional to mild coagulopathy. Furthermore, these patients recovered. The hemostatic parameters of most of the patients normalized between 96 and $120 \mathrm{~h}$ after the accident.

KEYWORDS: Lonomia obliqua caterpillar. Hemorrhagic syndrome. Coagulopathy. Fibrinolysis.

\section{INTRODUCTION}

A bleeding syndrome induced by skin contact with Lepidoptera (Saturniidae) caterpillars was described for the first time in Brazil by Alvarenga in 1912 ${ }^{1}$. At this time the responsible caterpillar genus was not known. A similar bleeding syndrome caused by the Lonomia achelous moth caterpillar (Saturniidae) was first described in Venezuela in $1967^{2,3}$ and was later reported in the North of Brazil ${ }^{4}$. Accidents with Lonomia obliqua ${ }^{5}$ caterpillars were observed for the first time in the South of Brazil in 1989 around the municipal districts of Passo Fundo (RS) and Chapecó (SC). By 1992, accidents with the caterpillars assumed epidemic proportions as incidence of such accidents grew annually. The main clinical characteristic of Lonomia $(L)$ obliqua accidents is a hemorrhagic syndrome associated with acute renal failure ${ }^{6,7}$. In general, the symptoms include local pain and burning, headache, nausea and vomiting, extensive ecchymosis in the contact areas, hematomas, gingival 
bleeding, epistaxis, hematemesis, melena, hematuria and metrorrhagia ${ }^{8,9}$. Acute renal failure and intracerebral bleeding are among the most severe complications of L. obliqua accidents and are also among the principal causes of death ${ }^{7,10,11}$.

Two procoagulant toxins have been identified in L. obliqua bristle extract, i.e., a factor $\mathrm{X}$ activator ${ }^{12}$ and a prothrombin activator serine protease ${ }^{13}$, and these toxins are most likely responsible for the intravascular thrombin formation that directly consumes the coagulation factors ${ }^{14}$.

The lethality of lonomic envenomation in the absence of specific treatment is 1.5 to $2.0 \%$, which is approximately 3 to 4 times greater than the lethality of snakebites ${ }^{15}$. Before serum therapy, previous experiences in Venezuela showed that replacement therapies with whole blood, fresh or frozen plasma, or cryoprecipitates contribute to the adverse clinical consequences of envenomation most likely because this type of treatment provides additional clotting factors that exacerbate the intravascular coagulation induced by the circulating toxins. The cessation of clinical evidence of bleeding has been reported following treatment with purified human fibrinogen and antifibrinolytic drugs, such as aprotinin and $\varepsilon$-amino caproic acid (EACA) ${ }^{3,16}$.

In Venezuela, skin contact with Lonomia caterpillars is mainly treated using Trasylol (aprotinin), and in Brazil, this condition is successfully managed using antilonomic serum therapy, which is effective in normalizing coagulation disturbances and hemorrhagic syndrome ${ }^{17,18,19}$. Moreover, the number of fatal cases is reduced with the use of serum therapy ${ }^{15}$. Studies of patients envenomed by L. obliqua caterpillars have shown that at the time of arrival at the hospital, a consumption coagulopathy associated with intravascular thrombin generation triggering secondary fibrinolysis ${ }^{9}$. In contrast, patients envenomed by Lonomia achelus caterpillars exhibit a primary fibrinolytic action ${ }^{16}$ due to their fibrinolytic enzymes. Despite these results, the complex pathological mechanism by which the hemorrhagic syndrome is caused by $L$. obliqua envenomation remains incompletely elucidated. The presence of high amounts of dimer-D in some patients in combination with nearly normal level of fibrinogen is still not well explained and neither are the rare thrombocytopenia events in patients with moderate and severe coagulopathies. The majority of reports present only the coagulation factor levels at admission. Here, we present a long-term follow-up clinical and laboratory data study concerning hemostatic disturbances in patients who had been envenomed by L. obliqua in Brazil. Our results show that the majority of patients who present with incoagulable blood without bleeding can normalize within 96-120 h after contact with the caterpillars. In contrast, patients who are treated with Lonomia antivenom recover within $20 \mathrm{~h}$ of treatment ${ }^{19}$ and thus avoid the considerable risks of bleeding and some systemic complications.

\section{MATERIAL AND METHODS}

\section{Patients}

The study was performed with 14 patients (Ps) who were admitted to the Hospital São Vicente de Paulo (HSVP), Passo Fundo, Rio Grande do Sul, Brazil, during the summers of 1993 and 1994 when Lonomia antivenom was not yet available for treatment. Patients with a history of contact with caterpillars and with some clinical evidence of envenomation (local pain, edema, bleeding, hematomas, etc.) and patients who brought the caterpillars to the clinic were considered in this study. These caterpillars were sent to the Instituto Butantan (IBu), São Paulo, Brazil for species identification. The patients were classified into the following four clinical groups based on the treatment experience at the hospital: Grade 0 patients were asymptomatic with no blood coagulation changes or bleeding of any type during $72 \mathrm{~h}$ of follow-up; Grade I patients exhibited bleeding symptoms with blood coagulation changes (i.e., incoagulable blood or prolonged clotting times); Grade II patients experienced ecchymosis, epistaxis, gingival bleeding, hematomas, bleeding from scars or recent wounds with no hemodynamic changes, and altered blood coagulation parameters; and Grade III patients exhibited macroscopic hematuria and hemorrhages in the digestive tract, lungs, peritoneum and central nervous system. The bleeding was occasionally accompanied by hemodynamic disturbances, acute renal failure, respiratory failure, adynamic ileum, changes in cognition, and/or altered blood coagulation parameters (Table 1).

This study was approved by the Ethics Committee of the HSVP (RS), Brazil. Written informed consent to participate was obtained from the patients or their relatives.

\section{Blood samples}

The first venous blood sample was either obtained shortly after admission (P01, P03, P04, P05, P11, P12, and P14), after the patient was under observation at the hospital for 5, 13, or $16 \mathrm{~h}$ (P06, P07, and P08), or 1 (P02 and P13), 3 or 4 days (P09 and P10,) before being included in the study. The delay times between blood collection and the assays are indicated in Table 2.

Blood was collected in $10 \%$ EDTA-Na ${ }_{2}$ with $10 \mu \mathrm{L}$ of antilonomic serum produced by the IBu (SP) for the laboratory analyses. For the biochemical analysis, serum samples were routinely collected and assayed in the HSVP laboratory. The coagulation assays were performed 
Table 1 - Background information on 14 patients on admission to HSVP

\begin{tabular}{lllll}
\hline Patient & Site of contact, age, sex & $\begin{array}{c}\text { Interval* } \\
\text { (hours) }\end{array}$ & Grade & \\
\hline 01 & R. hand (fingers), 25, M. & 7 & 0 & - \\
02 & - 3, M & 24 & 0 & - \\
03 & Back, 12, M & 6 & I & L. pain, erythema, cephalea, GID, dizziness \\
04 & R. hand, 7, M & 7 & I & L. pain, edema \\
05 & R. hand, 36, M & 7 & I & L. pain, cephalea, dizziness \\
06 & Le. forearm, 13, F & 7 & I & L. pain, edema, cephalea \\
07 & Le. hand (finger), 8, M & 8 & I & L. pain, erythema, cephalea, GID \\
08 & R. hand (finger), 71, F & 24 & I & L. pain, erythema, cephalea, GID \\
09 & Le fingers, 63, F & 4 & I & L. and general pain, edema, cephalea, GID, dizziness \\
10 & R. hand, 8, F & 24 & I & L. pain, erythema, edema, arthralgia \\
11 & R. hand, 3, M & 48 & II & L. pain, ecchymosis, bleeding, hematomas \\
12 & R. thigh, 12, M & 120 & II & L. pain, ecchymosis, dizziness, gingivorrhagia, hematomas \\
13 & R. hand (fingers), 11, M & $<24$ & III & L. pain, erythema, macroscopic hematuria, hematoma (R. arm), \\
14 & R. hand, 14, F & 48 & III & L. pain, edema, post-trauma: pulmonary and peritoneal hemorrhagia., \\
& & & vomiting, hypotension
\end{tabular}

GID- gastrointestinal disturbance, M-male, F-female, R-right, Le-left, L-local. *- Time elapsed between accident and blood collection; HSVP- Hospital São Vicente de Paulo

Table 2 - Blood coagulation and fibrinolytic parameters in 12 patients after the accidents with Lonomia oblique caterpillar, on admission

\begin{tabular}{|c|c|c|c|}
\hline Assays & Patients $\mathrm{X} \pm$ SEM & Min-max values & (Normal $X_{ \pm}$SEM ) \\
\hline Fibrinogen (g/L) & $0.7 \pm 0.6$ & $0.1-1.9$ & $2.1 \pm 0.1$ \\
\hline FII (\%) & $91.4 \pm 35.7$ & $50-189$ & $100 \pm 4$ \\
\hline $\mathrm{FV}(\%)$ & $60.6 \pm 56.0$ & $11-211$ & $111 \pm 9$ \\
\hline FVII (\%) & $130.8 \pm 98.1$ & $56-371$ & $132 \pm 34$ \\
\hline FVIII (\%) & $137.1 \pm 129.9$ & $51-529$ & $135 \pm 8$ \\
\hline FIX (\%) & $63.7 \pm 20.7$ & $28-95$ & $100 \pm 4$ \\
\hline $\mathrm{FX}(\%)$ & $112.7 \pm 54.8$ & $63-232$ & $128 \pm 24$ \\
\hline FXI (\%) & $107.9 \pm 34.5$ & $70-177$ & $131 \pm 6$ \\
\hline FXII (\%) & $73.1 \pm 43.3$ & $12-148$ & $113 \pm 14$ \\
\hline FXIII act (\%) & $45.8 \pm 18.8$ & $25-75$ & 100 \\
\hline FXIII ag (\%) & $79.5 \pm 18.4$ & $66-105$ & $60-150$ \\
\hline VWF (\%) & $105.0 \pm 66.1$ & $46-210$ & $50-150$ \\
\hline T-AT $(\mu \mathrm{g} / \mathrm{mL})$ & $63.3 \pm 23.8$ & $25-93$ & $4 \pm 0$ \\
\hline Protein C (\%) & $41.1 \pm 38.1$ & $2-109$ & $89 \pm 7$ \\
\hline AT-III act (\%) & $111.1 \pm 26.8$ & $73-163$ & 94 \\
\hline PLG (\%) & $45.2 \pm 13.0$ & $30-78$ & $76 \pm 9$ \\
\hline$\alpha_{2}-\mathrm{AP}(\%)$ & $51.4 \pm 21.3$ & $28-96$ & $106 \pm 9$ \\
\hline PAI (AU/mL) & $18.0 \pm 10.2$ & $2-33$ & $12 \pm 4$ \\
\hline FDP $(\mu \mathrm{g} / \mathrm{mL})$ & $70.0 \pm 107.3$ & $3-384$ & $3 \pm 0$ \\
\hline $\mathrm{D}-\mathrm{Di}(\mu \mathrm{g} / \mathrm{mL})$ & $26.6 \pm 38.8$ & $1-128$ & $0.5 \pm 0$ \\
\hline
\end{tabular}

Number of volunteers $=(5-7)$, F-factor, $\mathrm{vW}=$ von Willebrand, T-thrombin, AT $=$ Antithrombin, act $=$ activity, ag $=$ antigen 
on citrated plasma (160 mM sodium citrate with $2 \%$ antilonomic serum). This serum was added to prevent further in vitro activity of the venom. Plasma aliquots for fibrinogen determination were mixed with $50 \mu \mathrm{L}$ of 10\% EACA (Ipsilon, Química e Farmacêutica, NIKKHO Brazil LTDA, RJ, Brazil) before freezing. The plasma was immediately stored at $-20{ }^{\circ} \mathrm{C}$. Frozen aliquots were transported on dry ice to the IBu (SP) and maintained at $-70{ }^{\circ} \mathrm{C}$ until testing. All plasma samples were examined within three months of collection.

\section{Assays}

At the HSVP, the whole blood clotting time (WBCT) ${ }^{20}$, activated partial thromboplastin time (APTT) (Roche Diagnostics, Switzerland), and prothrombin time (PT) (Baxter Healthcare Corporation, Morgantown, WV, USA) were assayed. Additionally, hematological and biochemical assays were performed, and the platelet count was determined using conventional methods.

Human plasma samples deficient in the following factors were used for the clotting factor assays: II, VIII, $\mathrm{X}$, and XI (Behringwerke, Brazil); VII and IX (Baxter Healthcare Corporation, USA); XII (American Diagnostics, Germany); and V (prepared in the laboratory) ${ }^{21}$. The factor XIII level, antithrombin III activity, protein C (PC; Staclot protein $\mathrm{C}$ assay) level, plasminogen (PLG; Stachrom PLG) level, and alpha ${ }_{2}$-antiplasmin $\left(\alpha_{2}\right.$-AP; Stachrom antiplasmin) level were tested using Diagnostica Stago kits (Asnieres, France). Plasminogen activator inhibitor- 1 (PAI-1; Spectrolyse - enzymatic) was measured with an American Diagnostics kit. Immunological tests were used to measure the degradation products of fibrin/fibrinogen (FnDP/FgDP), and thrombin-antithrombin antigen (T-AT) was measured using an EIA kit system (Behringwerke, Brazil). Cross-linked fibrin fragments (D-dimer-[D-Di]) were measured using a latex agglutination immunoassay (Diagnostica Stago), and fibrinogen levels were assayed using the colorimetric method ${ }^{22}$. Total plasma protein was assayed via the method of Markwell et al. ${ }^{23}$ and haptoglobin was measured by electrophoresis on cellulose acetate ${ }^{24}$.

\section{RESULTS}

The majority of the 14 patients (Ps) were classified as Grade I $(n=8)$, two-were classified as grade II, two as Grade III, and two as Grade 0 (Table 1). After admission, the patients did not receive any specific treatment with the exceptions of P12 who had received a blood transfusion before she arrived at HSVP and P14 who received a transfusion of erythrocytes and the antifibrinolytic drug $\varepsilon$-amino-caproic acid (EACA). Two asymptomatic patients were excluded. Thus, the recoveries of the hemostatic parameters were assayed in 12 patients.

The time that elapsed from the accident to admission to the hospital varied between 4 and $120 \mathrm{~h}$. There was no relationship between this period and the seriousness of the envenomation, although the more severe cases were the patients who arrived at the hospital less than $24 \mathrm{~h}$ or more than $48 \mathrm{~h}$ after the accident (Table 1). Bleeding ceased without treatment within $48 \mathrm{~h}$ in all GII cases and in one GIII patient.

An overview of the envenomation kinetics (Figures 1,2) of these patients revealed accentuated fibrinogen reductions during the first hours after the accident that increased the hemostatic levels, but these levels did not reach the normal values. The coagulation and fibrinolytic factor assays of the 12 patients upon admission are presented in Table 2. Marked decreases in the levels of factors V and XIII and Protein C (PC) in the patients were observed during the initial hours after envenomation (Table 2). The FXIII activity levels remained at 50\% even after $192 \mathrm{~h}$. In contrast, the FXIII antigen levels remained within the normal range. The majority of the patients presented with FV levels between 70 and $100 \%$ at $72 \mathrm{~h}$ after envenomation. Accentuated decreases in PC were observed in all envenomation grades, and these values remained below normal during the analysis period (Figure 1). The recuperations were slower in the GII and GIII patients $(>120 \mathrm{~h})$ than in the GI $(>72 \mathrm{~h})$ patients (data not shown). Factor II was decreased upon admission in one mild case (58\%) and one severe case (50\%), and these levels remained decreased for 3 to 5 days (60 and 70\%). Similarly, factor VIII levels were also decreased in three patients $(51 \%)$, whereas two patients exhibited increased levels $(529 \%$ and $151 \%)$. The majority of the patients exhibited slightly reduced FIX levels (44-81\%) with the exception of one patient who had a normal level (102\%) $120 \mathrm{~h}$ after the accident. Regarding FXII, there were no changes with the exceptions two patients who presented with low levels (12 and 15\%). Von Willebrand factor and ATIII activity levels were normal in most of the patients, but one patient presented with an increased vWF level at $29 \mathrm{~h}(210 \%)$. Furthermore, the ATIII antigen levels were increased in 6/11 patients (between 196 and 200\%). The T-AT complex levels were increased upon admission in all patients (25-93 $\mu \mathrm{g} / \mathrm{mL})$; however, these levels normalized during the evolutions of the conditions (Figure 2).

The plasminogen and $\alpha_{2}$-antiplasmin levels were reduced upon admission. Both parameters increased but did not reach normal levels during the analysis period. Slight increases in the PAI-1 levels were observed at 6 and 24 h, PAI-I levels returned to normal after these time points (Figure 2). The 

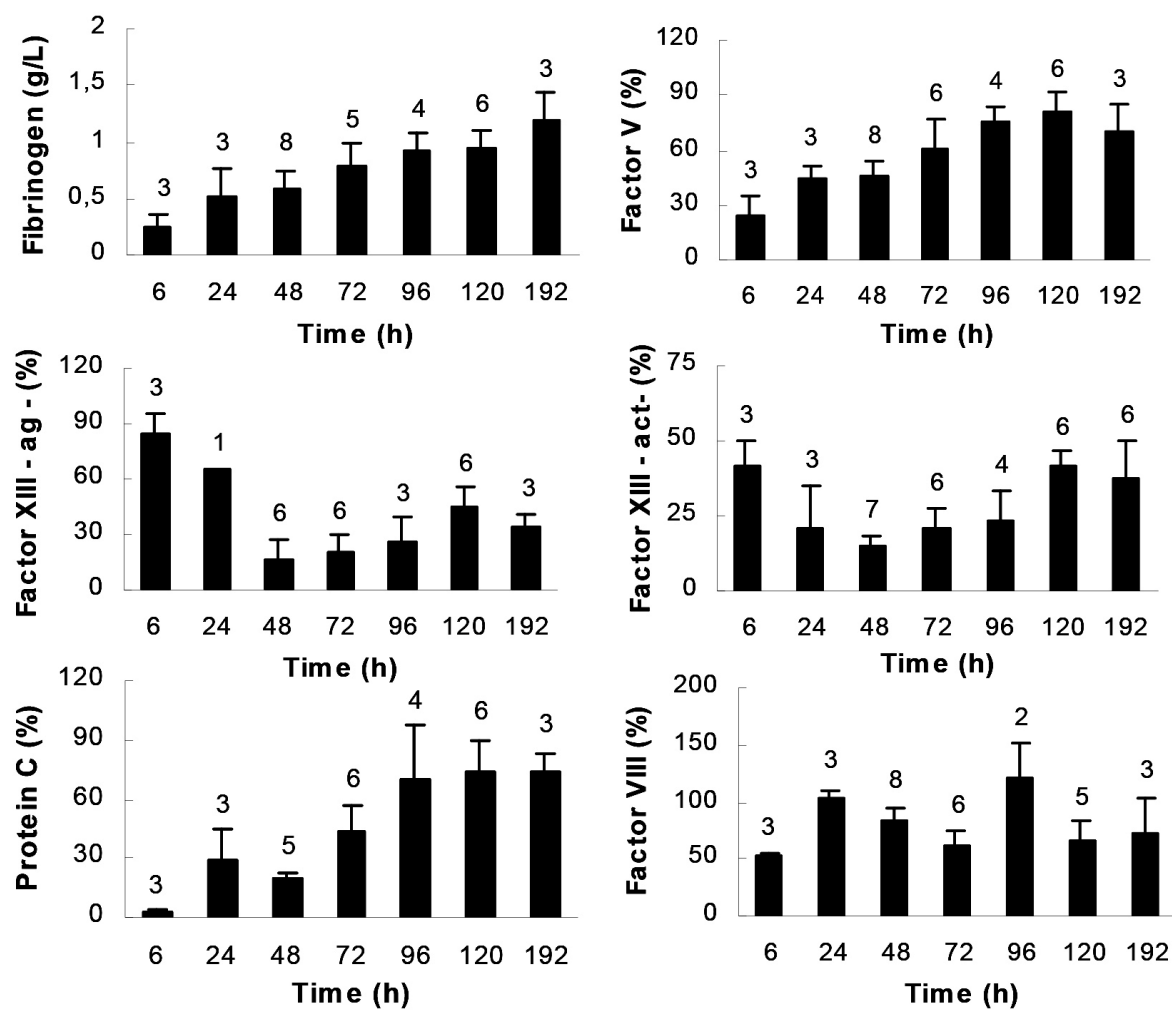

Figure 1 - Time-course of fibrinogen, factor V, factor XIII-ag, factor XIII-act, factor VIII and protein C consumption of 10 patients after contact with the Lonomia obliqua caterpillar. ag- antigen, act- activity, Bars represent the mean \pm SEM. Numbers over bars $=$ number of patients.
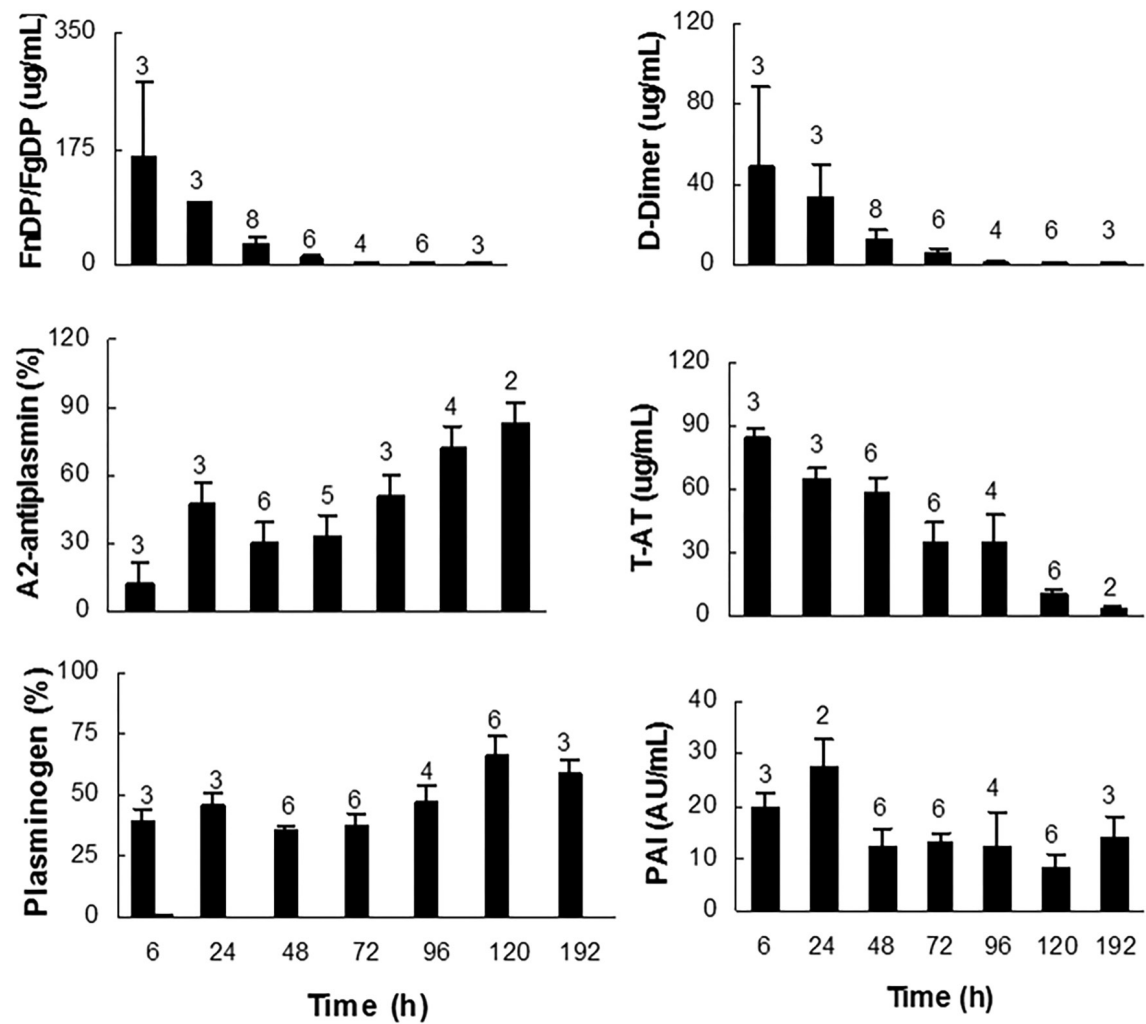

Figure 2 - Time-course of fibrin/fibrinogen degradation products (FnDP/FgDP), cross-linked fibrin fragment (D-Dimer), $\alpha_{2}$-antiplasmin, thrombin-antithrombin antigen (T-AT), plasminogen and plasminogen activator inhibitor (PAI) consumption of 10 patients after contact with the Lonomia obliqua caterpillar. Bars represent the mean \pm SEM. Numbers over bars - number of patients 
FnDP/FgDP and D-Di levels were increased in nearly all patients primarily at 6-7 $\mathrm{h}$ after the accidents. Higher levels (FnDP/FgDP: -384 $\mu \mathrm{g} / \mathrm{mL}$ and D-Di-128: $\mu \mathrm{g} / \mathrm{mL}$ ) were observed in one patient. All patients returned to normal levels after $120 \mathrm{~h}$ (Figure 2).

The hematological patient data that were collected upon admission $(n=8)$ revealed only one anemic patient with internal bleeding $\left(2.5 \times 10^{12}\right.$ red cells, $22 \%$ hematocrit and $7.6 \mathrm{~g} / \mathrm{L}$ hemoglobin). Slight leukocytosis with differential counts that remained within normal limits was observed. Three of the patients presented with moderate leukocytosis $\left(12-14.0 \times 10^{9} / \mathrm{L}\right)$ without any significant alterations, and only a single patient presented with neutrophilia without a leftward deviation. Thrombocytopenia was observed in only one patient at $40 \mathrm{~h}$ after admission $\left(51 \times 10^{9} / \mathrm{L}\right)$, and the platelet level remained below normal $\left(65 \times 10^{9} / \mathrm{L}\right)$ even after $72 \mathrm{~h}$. One patient who was admitted with normal platelet levels exhibited a slight decrease at $120 \mathrm{~h}$ after the accident $\left(131 \times 10^{9} / \mathrm{L}\right)$. Four patients exhibited reduced total protein levels $(4.9-5.8 \mathrm{~g} / \mathrm{dL})$ that did not return to normal $(7.0 \pm 0.5)$ until they were discharged, and the other patients exhibited levels between 6.0 and $7.4 \mathrm{~g} / \mathrm{dL}$ during the analysis period. Low haptoglobin levels (1.3-1.7 g/L) were observed in 3 of 5 studied patients and probably resulted from subclinical hemolysis.

\section{DISCUSSION}

This is the first study of patients $(\mathrm{n}=12)$ who had been envenomed by contact with the L. obliqua caterpillar to conduct monitoring and long-term follow-up of the clinical and (laboratory) coagulation parameters until discharge.

The patients bleeding disorders following contact with the caterpillars were spontaneous and occurred in any part of the body but generally occurred in areas that were injured or had previous wounds.

The patients with low fibrinogen levels also presented with low FV, PC, FXIII, PLG and $\alpha_{2}$-AP levels. In contrast, these patients exhibited higher T-AT, FnDP/FgPD, and D-Di levels, which suggests the occurrence of disseminated intravascular coagulation (DIC) and fibrinolysis activation. Our follow-up laboratory data indicated that there was no relationship of the time elapsed from the accident until hospital admission with the severity of the condition. However, the GI patients who were admitted between 7 and $29 \mathrm{~h}$ after the accident exhibited higher levels of FnDP/FgDP and D-Di than the patients who were admitted $96 \mathrm{~h}$ after the accident and presented with near normal levels. Additionally, the patients who were in critical condition (GII and GIII) an arrived at the hospital $48 \mathrm{~h}$ after the accident exhibited lower levels of FnDP/FgDP and $\mathrm{D}$-Di, which suggests that these alterations are more strongly related to the time of the accident than to the seriousness of the envenomation. Similar results have been observed in patients who were poisoned by L. achelous caterpillars and presented with low $\mathrm{FnDp} /$ FgDP levels during the first days after envenomation ${ }^{16}$. These consumption coagulopathies seem to be induced mainly by the FII and FX procoagulant activators that are present in both L. obliqua bristle extracts ${ }^{12,13}$ and Lonomia achelous $^{25,26}$ as previously proposed elsewhere ${ }^{8,14}$. Despite the formation of intravascular thrombin, which is detected as an elevation in the T-AT complex, moderate thrombocytopenia $\left(138 \times 10^{9} / \mathrm{L}\right)$ was observed in only one patient. In Venezuela, patients poisoned by L. achelous were treated with purified human fibrinogen with aprotinin, and in some cases, EACA was administered after aprotinin. In our study, one patient (Grade III) was treated with an antifibrinolytic drug (EACA) in Ringer solution for three days (total of $15 \mathrm{~g}$ ), received packed red blood cells over four days $(1.5 \mathrm{~L})$ and was discharged ten days after admission in a normal condition. Since 1995, there has been a reduction in the mortality rate due to the introduction of an antilonomic serum for the treatment of L. obliqua envenomation ${ }^{19,27}$. Our present study revealed a severe consumption coagulopathy characterized by hypofibrinogenemia and activation of the fibrinolytic system that was prolonged for more than eight days during recovery. The abnormalities related to blood coagulation and fibrinolytic factors were similar in all the patients in the study, which indicates that the severity of the accident could not be predicted by changes in the hemostatic parameters. Consequently, alterations of coagulation without thrombocytopenia do not define the seriousness of the accident; however, these parameters are relevant when evaluating the patient recovery, and treatment efficacy.

The comparative study between the patient who received blood and EACA treatment and the patients who did not receive any treatment after admission suggested that blood transfusion, even at $120 \mathrm{~h}$, was responsible for the significantly lower levels of FV, FXIII, PC and PLG and the higher levels of T-AT, which suggests that whole blood infusion can be responsible for blood coagulation activation as has been found in cases hemorrhagic diathesis induced by contact with L. achelous ${ }^{16}$. However, $240 \mathrm{~h}$ after the accidents, there were no differences in the fibrinogen levels, which were at hemostatic levels. Moreover, the FXIII levels remained below normal values in all patients.

Material obtained from the venomous fluid of the secretory system of $L$. obliqua has been shown to contain an enzyme with fibrinolytic action ${ }^{28}$. Consequently, in the 
patients in this study, fibrinolysis could have occurred due to the direct action of this enzyme (lonofibrase), which may have been responsible for both the primary fibrinolytic activity and the secondary fibrinolysis activation that were induced by procoagulant activities ${ }^{29}$. The decrease in PLG was not related to the interval between the accident and the analysis. In contrast, the PAI-1 levels at 7 and $29 \mathrm{~h}$ after the accidents were greater than the levels at 48 and 96 h. Interestingly, all patients, including the asymptomatic ones, exhibited FXIII levels that were below normal values during the analyzed period. Studies of $L$. achelous hemolymph and its fractions (i.e., lonomin $\mathrm{V}$ ) have shown that this enzyme has a dose-dependent relationship with FXIII inactivation, and this effect may play a major role in the bleeding syndrome induced in humans ${ }^{30}$. This mechanism could be one of the factors that are involved in the hemorrhagic syndrome that occurs following L. obliqua exposure, which is also associated with a decrease in FXIII. In vitro studies and experimental envenomations of rats and rabbits with $L$. achelous caterpillar bristle extract as well as studies in patients indicate that FXIII reduction is related to the cleavage of subunit A of the factor XIII molecule associated with the inhibitor of crosslinking ${ }^{30}$. Consequently, the formation of D-Di is not substantially increased. These results suggest that, in vivo, the hemorrhagic syndrome can also be provoked by the proteolysis of FXIII. In contrast, Zannin et al. ${ }^{9}$, who obtained data only upon patient arrival at the hospital, reported high levels of D-Di in the majority of the patients, although some of these patients presented with normal levels of fibrinogen. Thus, it is important to consider that although some groups have reported that no fibrinolytic activity is induced by L. obliqua exposure and that any fibrinolytic activities are secondary ${ }^{26}$, another group presented clear evidence of fibrinogenolytic activity ${ }^{28,29}$. Thus, the mechanism of this envenomation is not yet entirely understood. Some components, such as fibrinogenolytic agents, kininogen, serpins, lectins, and PLA, which have been described in a catalog of $L$. obliqua cDNAs and proteins ${ }^{29}$, may also contribute to the symptoms manifested by patients who experience this type of accident. Moreover, kininogens have been shown to possess antithrombotic properties in vivo at low concentrations of thrombin ${ }^{31}$. Lonomia obliqua bristle extract actives human platelets to induce adhesion and aggregation through a calcium-dependent mechanism that is triggered by the phospholipase A2 that is present in this extract ${ }^{32}$. Most severely affected patients present thrombocytopenia, which is related to morbidity and bleeding events. Rats that are experimentally envenomed with Lonomia obliqua extract have been shown to present with slight thrombocytopenia, but significant hypoaggregation induced by intravascular nitric oxide and fibrin/ fibrinogen degradation products can be elicited by hemostatic disturbances ${ }^{33}$.

Approximately $2 \%$ of patients envenomed via contact with $L$. obliqua caterpillars develop acute renal failure, and the administration of antilonomic serum reduces the mortality due to the severity of renal impairment; however, antilonomic serum does not decrease this incidence ${ }^{27}$. An experimental research has shown that treatment with Lonomia antivenom within $2 \mathrm{~h}$ of envenomation normalizes biochemical alterations, whereas treatment after $6 \mathrm{~h}$ does not elicit the recovery of these parameters despite the efficacy of specific antivenom therapy in reversing hemostatic disturbances ${ }^{34}$.These results may explain the observations in 286 patients. The patients who received care more than $48 \mathrm{~h}$ after the contact exhibited a greater probability (11\%) of progressing to acute renal failure than those who arrived at the hospital within the first $48 \mathrm{~h}(2.9 \%)$ indicating that the time elapsed between the contact and the hospital care is an important factor in terms of the occurrence of acute renal failure (HSVP, Passo Fundo, 1989/02 to 1995/07, unpublished data, Duarte AC). The mechanism responsible for renal dysfunction following the accidental exposure in humans is not yet well understood, but hemodynamic changes secondary to bleeding or direct nephrotoxicity are possible explanations. It has been suggested that renal dysfunction could be related to a disseminated intravascular coagulation with a massive deposition of fibrin in the glomerular capillaries. Cortical and tubular necrosis resulting from intravascular coagulation is also possible because, in previous studies, 4 of 39 acute renal failure cases have never recovered renal function ${ }^{11,27}$. In our study, only one patient, who was admitted to the hospital $48 \mathrm{~h}$ after the accident, presented with an increased creatinine $(2.7 \mathrm{mg} / \mathrm{dL})$ level, which normalized after $24 \mathrm{~h}$. Experimental L. obliqua envenomation in rats has been shown to elicit acute kidney injury with tubular necrosis associated with renal inflammation, fibrosis and increased vascular permeability. Additionally, the presence of Lonomia venom in the renal tissue is associated with morphological and functional alterations that are suggestive of a direct nephrotoxic action ${ }^{35}$.

The patients in this study presented with different levels of envenomation and received palliative treatment without antilonomic serum therapy, and the laboratory parameters normalized after $196 \mathrm{~h}$. However, treatment with antilonomic serum must be applied because it is the most efficient treatment and reverses the hemostatic disturbances as well as the bleeding disorders in less than $24 \mathrm{~h}$ after treatment ${ }^{19}$. 


\section{ACKNOWLEDGEMENTS}

This paper is dedicated to the memory of Dr. Eva Maria Antonia Kelen, who started this line of investigation at Instituto Butantan. The authors would like to thank Neusa Tadeu Penas Picon, Sandra Corrallo de Tomy, Sandra Conceição Barreto Castro, and Anita Mitico TanakaAzevedo for their technical assistance.

\section{FUNDING}

This work was partially supported by the grant Fundação de Amparo à Pesquisa do Estado de S Paulo (FAPESP, 97/01193-2, 2010/19419-3) and Conselho Nacional de Desenvolvimento Científico e Tecnológico (CNPq 303711/2007-8), grant to ISSM.

\section{REFERENCES}

1. Alvarenga Z. As tatoranas. In: Anais do VII Congresso Brasileiro de Medicina Cirúrgica; 1912; Belo Horizonte, Minas Gerais, Brasil. v.2. p.132-5.

2. Arocha-Piñango CL. Fibrinolysis producida por contato com orugas. Acta Cient Venez. 1967;18:136-9.

3. Arocha-Piñango CL, Layrisse M. Fibrinolysis produced by contact with a caterpillar. Lancet. 1969;1:810-2.

4. Fraiha H, Ballarini AJ, Leão RN, Costa Jr D, Dias LB. Sindrome hemorrágica por contato com larvas de mariposa (Lepidoptera, Saturniidae). In: Fundação Serviços de Saúde Pública, editor. Instituto Evandro Chagas: 50 anos de contribuição às ciências biológicas e à medicina tropical. Belém: Ministério da Saúde: Fundação Serviços de Saúde Pública; 1986. p.811-20.

5. Lemaire C. The Saturniidae of America. Keltern; Goecke \& Evers; 2002.

6. Duarte AC, Caovilla J, Lorini I, Lorini D, Mantovani G, Sumida $\mathrm{J}$, et al. Insuficiência renal aguda por acidentes com lagartas. J Bras Nefrol. 1990;12:184-7.

7. Burdmann EA, Antunes I, Saldanha LB, Abdulkader RC. Severe acute renal failure induced by the venon of Lonomia caterpillars. Clin Nephrol. 1996;46:337-9.

8. Kelen EM, Picarelli ZP, Duarte AC. Hemorrhagic syndrome induced by contact with caterpillars of the genus Lonomia (Saturnidae, hemileucinae). Toxin Rev. 1995;14:283-308.

9. Zannin M, Lourenço DM, Motta G, Dalla Costa LR, Grando M, Gamborgi GP, et al. Blood coagulation and fibrinolytic factors in 105 patients with hemorrhagic syndrome caused by accidental contact with Lonomia obliqua caterpillars in Santa Catarina, Southern Brazil. Thromb Haemost. 2003;89:355-64.

10. Duarte AC, Crusius PS, Pires CA, Schilling MA, Fan HW. Intracerebral haemorrhage after contact with Lonomia caterpillars. Lancet. 1996;348:1033.
11. Abdulkader RC, Barbaro KC, Barros E, Burdmann EA. Nephrotoxicity of insect and spider venoms in Latin America. Semin Nephrol. 2008;28:373-82.

12. Donato JL, Moreno RA, Hyslop S, Duarte A, Antunes E, Le Bonniec BF, et al. Lonomia obliqua caterpillar spicules trigger human blood coagulation via activation of factor $\mathrm{X}$ and prothrombin. Thromb Haemost. 1998:79:539-42.

13. Reis CV, Portaro FC, Andrade AS, Fritzen M, Fernandes BL, Sampaio CA, et al. A prothrombin activator serine protease from the Lonomia obliqua caterpillar venom (Lopap): biochemical characterization. Thrombs Res. 2001;102:427-36.

14. Reis CV, Farsky SH, Fernandes BL, Santoro ML, Oliva ML, Mariano M, et al. In vivo characterization of Lopap, a prothombin activator serine protease from the Lonomia obliqua caterpillar venom. Thromb Res. 2001;102:437-43.

15. Brasil. Ministério da Saúde. Fundação Nacional de Saúde. Manual de diagnóstico e tratamento de acidentes por animais peçonhentos. $2^{\mathrm{a}}$ ed. Brasília: Ministério da Saúde: Fundação Nacional de Saúde; 2001. p.67-76.

16. Arocha-Piñango CL, de Bosch NB, Torres A, Goldstein C, Nouel A, Argüello A, et al. Six new cases of a caterpillar-induced bleeding syndrome. Thromb Haemost. 1992;67:402-7.

17. da Silva WD, Campos CM, Gonçalves LR, Sousa-e-Silva MC, Higashi HG, Yamagushi IK, et al. Development of an antivenom against toxins of Lonomia obliqua caterpillars. Toxicon. 1996;34:1045-9.

18. Rocha-Campos AC, Gonçalves LR, Higashi HG, Yamagushi IK, Fernandes I, Oliveira JE, et al. Specific heterologous $\mathrm{F}(\mathrm{ab})^{2}$ antibodies revert blood incoagulability resulting from envenoming by Lonomia obliqua caterpillars. Am J Trop Med Hyg. 2001;64:283-9.

19. Caovilla JJ, Barros EJ. Efficacy of two different doses of antilonomic serum in the resolution of hemorrhagic syndrome resulting from envenoming by Lonomia obliqua caterpillars: a randomized controlled trial. Toxicon. 2004;43:811-8.

20. Lee RI, White PD. A clinical study of the coagulation time of blood. Am J Med Sci. 1913;145:495-503.

21. Denson KW. Techniques (Appendix II). In: Biggs R, editor. Human blood coagulation, haemostasis and thrombosis. $2^{\text {nd }}$ ed. Oxford: Blackwell; 1976. p.670-769.

22. Ratnoff OD, Menzie C. A new method for the determination of fibrinogen in small samples of plasma. J Lab Clin Med. 1951;37:316-20.

23. Markwell MA, Haas SM, Bieber LL, Tolbert NE. A modification of the Lowry procedure to simplify protein determination in membrane and lipoprotein samples. Anal Biochem. 1978;87:206-10.

24. Barreto OC, Nonoyama K, Mizukami S, Maspes V. Método modificado de dosagem de haptoglobina por eletroforese em acetato de celulose. Rev Bras Patol Clin. 1984;20:104-6. 
25. Guerrero B, Arocha-Piñango CL. Activation of human prothrombin by the venom of Lonomia achelous (Cramer) caterpillars. Thromb Res. 1992;66:169-77.

26. Carrijo-Carvalho LC, Chudzinski-Tavassi AM. The venom of the Lonomia caterpillar: an overview. Toxicon. 2007;49:741-57.

27. Gamborgi GP, Metcalf EB, Barros EJ. Acute renal failure provoked by toxin from caterpillars of the species Lonomia oblique. Toxicon. 2006;47:68-74

28. Pinto AF, Dobrovolski R, Veiga AB, Guimarães JA. Lonofibrase, a novel $\alpha$-fibrinogenase from Lonomia obliqua caterpillars. Thromb Res. 2004;113:147-54.

29. Veiga AB, Ribeiro JM, Guimarães JA, Francischetti JM. A catalog for transcripts from venomous structures of the caterpillar Lonomia obliqua: identification of the proteins potentially involved in the coagulation disorder and hemorrhagic síndrome. Gene. 2005;355:11-27.

30. Guerrero B, Arocha-Piñango CL, Gil San Juan A. Degradation of human factor XIII by lonomin V, a purified fraction of Lonomia achelous (Cramer) caterpillar venom. Thromb Res. 1997;87:171-81.

31. Colman RW, White JV, Scovell S, Stadnicki A, Sartor RB. Kininogens are antithrombotic proteins in vivo. Arterioscler Thromb Vasc Biol. 1999;19:2245-50.
32. Berger M, Reck J Jr, Terra RM, Beys-da-Silva WO, Santi L, Pinto $\mathrm{AF}$, et al. Lonomia obliqua venomous secretion induces human platelet adhesion and aggregation. J Thromb Thrombolysis. 2010;30:300-10.

33. Berger M, Reck J Jr, Terra RM, Pinto AF, Termignoni C, Guimarães J. Lonomia obliqua caterpillar envenomation causes platelet hypoaggregation and blood incoagulability in rats. Toxicon. 2010;55: 33-44.

34. Berger M, Beys-da-Silva WO, Santi L, Oliveira IM, Jorge PM, Henriques JA, et al. Acute Lonomia obliqua caterpillar envenomation-induced physiopathological alterations in rats: Evidence of new toxic venom activities and the efficacy of serum therapy to counteract systemic tissue damage. Toxicon. 2013;74:179-92.

35. Berger M, Santi L, BeysdaSilva WO, Oliveira FM, Caliari MV, Yates JR 3rd, et al. Mechanisms of acute kidney injury induced by experimental Lonomia obliqua envenomation. Arch Toxicol. 2015;89:459-83. 